\title{
Case Report: Co-occurrence of Pituitary Adenoma with Suprasellar and Olfactory Groove Meningiomas
}

\author{
Kai-Zheong Lim ${ }^{1,2,3^{*}}$, Tony Goldschlager ${ }^{1,2,3}$, Ronil V. Chandra ${ }^{2,3,4}$, Jonathan Hall ${ }^{1}$, Brent Uren ${ }^{5}$, Michael Pullar ${ }^{1}$ \\ 1. Department of Neurosurgery, Monash Health, Clayton, Victoria, Australia \\ 2. Department of Nursing and Health, Faculty of Medicine, Monash University, Clayton, Victoria, Australia. \\ 3. Department of Surgery, Faculty of Medicine, Monash University, Clayton, Victoria, Australia. \\ 4. Diagnostic and Interventional Neuroradiology, Monash Health, Melbourne, Victoria, Australia. \\ 5. Department of Otolaryngology, Head and Neck Surgery, Monash Medical Centre, Clayton, Victoria, Australia.
}

Cftation: Lim, K. Zh., Goldschlager, T., Chandra, R. V., Hall, J., Uren, B., \& Pullar, M. (2016). Co-occurrence of pituitary adenoma with suprasellar and olfactory groove meningiomas . Basic and Clinical Neuroscience, 7(4), 361-365. http://dx.crossref.org/10.15412/J.BCN.03070409

dof': http://dx.crossref.org/10.15412/J.BCN.03070409

Article info:

Received: 05 April 2016

First Revision: 30 April 2016

Accepted: 22 June 2016
Key Words:

Pituitary tumors,

Olfactory groove

meningioma, Endoscopic

surgical procedure,

Multiple meningioma

\begin{abstract}
A B S T RA C T
Introduction: The co-existence of pituitary adenoma and meningioma is extremely rare. It is even rarer in patients with no previous known risk factors for either tumour. Here, we present a case of synchronous non-functioning pituitary adenoma with suprasellar and olfactory groove meningiomas in a patient without previous irradiation.

Methods: The tumours were diagnosed on MRI in the 65-year-old patient who presented with patchy visual deficits. The decision was made to undergo surgery for resection of the suprasellar meningioma and the pituitary adenoma, leaving the small olfactory groove meningioma intact. Extended endoscopic transsphenoidal surgery was performed.

Results: Macroscopic clearance was achieved for pituitary macroadenoma and suprasellar meningioma. Postoperatively, visual field tsting and pituitary axis hormonal levels were normal The pituitary macroadenoma was confirmed to be a non-functioning pituitary adenoma. The meningioma was diagnosed to be of WHO grade 1 .
\end{abstract}

Conclusion: The rationale for choosing such management option, including its risks and benefits in this challenging patient is discussed.

\section{Introduction}

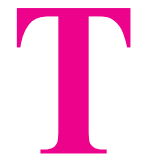

he concurrent existence of pituitary adenoma and meningioma is extremely rare and even rarer in patients with no previous known risk factors for either tumour. Here, we present a first reported case of synchronous non-functioning pituitary adenoma with suprasellar and olfactory groove meningiomas in a patient without previous irradiation.

\section{Case Presentation}

A coexistence of pituitary adenoma with suprasellar and olfactory groove meningiomas was discovered in a 65-year-old woman on MRI performed following visual

* Corresponding Author:

Kai-Zheong Lim, MBBS

Address: 1/61, Green Street, Wangaratta, Victoria 3677, Australia

Tel: +94 (61) 4786862

E-mail: kzlim2@student.monash.edu 
symptoms and an episode of self-resolving vertigo. She had no previous cranial irradiation or family history of inherited conditions. Visual acuity was normal but visual field examination revealed patchy defects inconsistent with compression of the optic apparatus. She had no clinical features of endocrinopathy, frontal lobe, or neurocutaneous syndromes.

Contrast-enhanced MRI demonstrated a large 16×13×20 $\mathrm{mm}$ pituitary lesion consistent with pituitary macroadenoma and, immediately adjacent to it, a $15 \times 13 \times 13 \mathrm{~mm}$ homogenous enhancing lesion arising from tuberculum

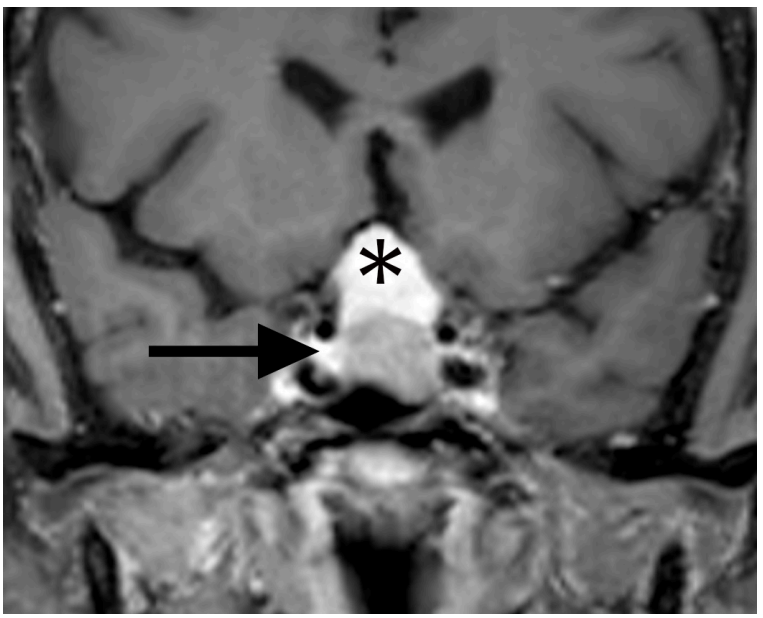

NEUR:SCIENCE

Figure 1. Preoperative T1-weighted postcontrast coronal MRI revealing a homogenously enhancing suprasellar meningioma (asterisk) and an adjacent pituitary macroadenoma of variable intensity in the pituitary region (straight black arrow). The suprasellar meningioma extends into the interhemispheric fissure.

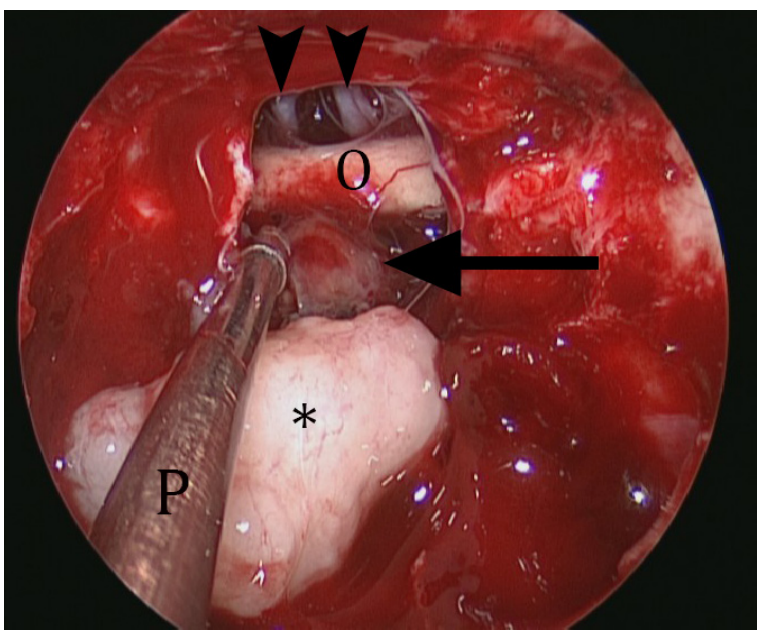

NEUR SCIENCE

Figure 3. Intraoperative photograph demonstrating that the suprasellar meningioma (asterisk) is first dissected off with an endonasal probe $(\mathrm{P})$, while the overlying anterior cerebral arteries (black arrowheads), optic chiasm $(\mathrm{O})$, and pituitary macroadenoma (straight black arrow) are visible. sella compressing the optic apparatus (Figure 1,2). A third small $6 \times 5 \mathrm{~mm}$, homogenously enhancing lesion with a dural tail was found along the olfactory groove, consistent with an olfactory groove meningioma (OGM) (Figure 2). Preoperative pituitary hormonal evaluation was normal: follicle-stimulating hormone (FSH) of 30.2 IU/L (reference range: $<100 \mathrm{IU} / \mathrm{L}$ in postmenopausal women), thyroid stimulating hormone (TSH) of 2.15 $\mathrm{mIU} / \mathrm{L}$ (reference range: $0.35-5.50 \mathrm{mIU} / \mathrm{L}$ ), luteinizing hormone $(\mathrm{LH})$ of $13.2 \mathrm{IU} / \mathrm{L}$ (reference range: $<62 \mathrm{IU} / \mathrm{L}$ in postmenopausal women), growth hormone $(\mathrm{GH})$ of $1.2 \mu \mathrm{g} / \mathrm{L}$ (reference range: $<5 \mu \mathrm{g} / \mathrm{L}$ ), adrenocorticotro-

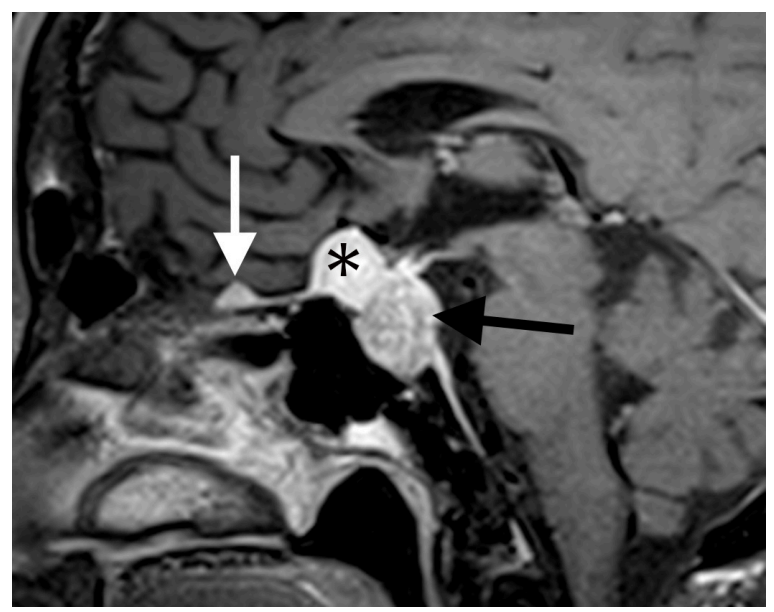

NEUR:SCIENCE

Figure 2. Preoperative T1-weighted postcontrast sagittal MRI image revealing a smaller olfactory groove meningioma with dural tail (straight white arrow) noted in the sagittal section along with suprasellar meningioma (asterisk) and the pituitary macroadenoma (straight black arrow).

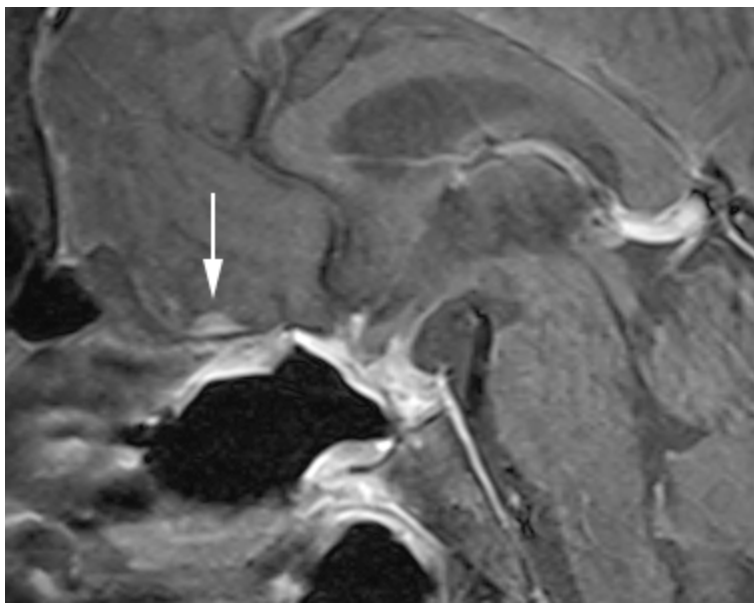

NEUR:SCIENCE

Figure 4. Postoperative T1-weighted postcontrast sagittal MRI revealing persistent olfactory groove meningioma with no change in size. Pituitary macroadenoma and the adjacent suprasellar meningioma were resected with no residual tumour. 


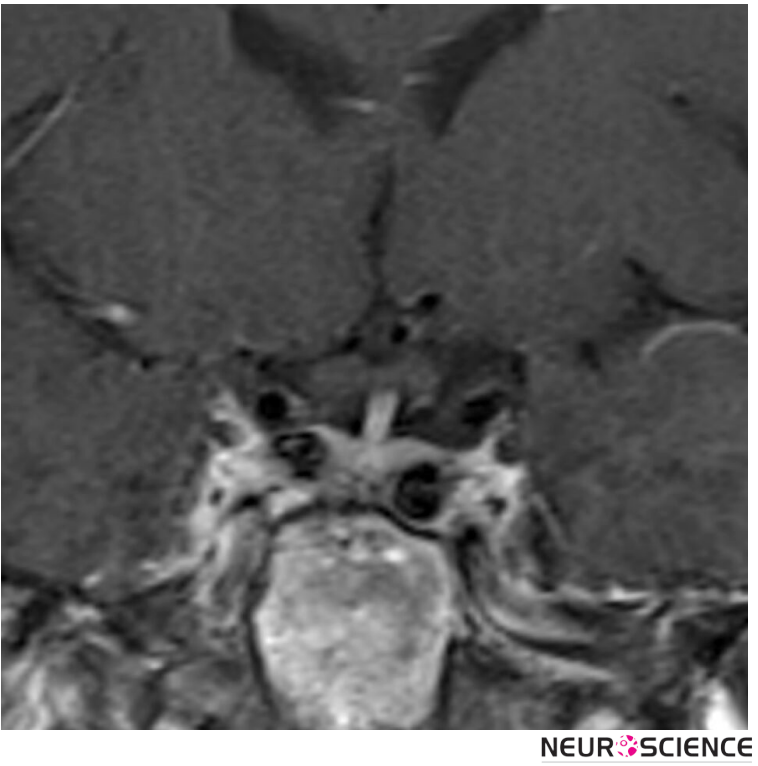

Figure 5. Postoperative T1-weighted postcontrast coronal MRI revealing absence of pituitary adenoma and suprasellar meningioma, which have been resected.

phic hormone (ACTH) of $22 \mathrm{pg} / \mathrm{mL}$ (reference range: $<46 \mathrm{pg} / \mathrm{mL}$ ), prolactin (PRL) of $18.8 \mu \mathrm{g} / \mathrm{L}$ (reference range: $<25 \mu \mathrm{g} / \mathrm{L})$

\section{Treatment Protocol}

After discussion with the patient, the decision was made to resect the 2 sellar region tumours (because of their size) to decompress the optic apparatus. Meanwhile, the smaller asymptomatic OGM was managed conservatively with serial imaging.

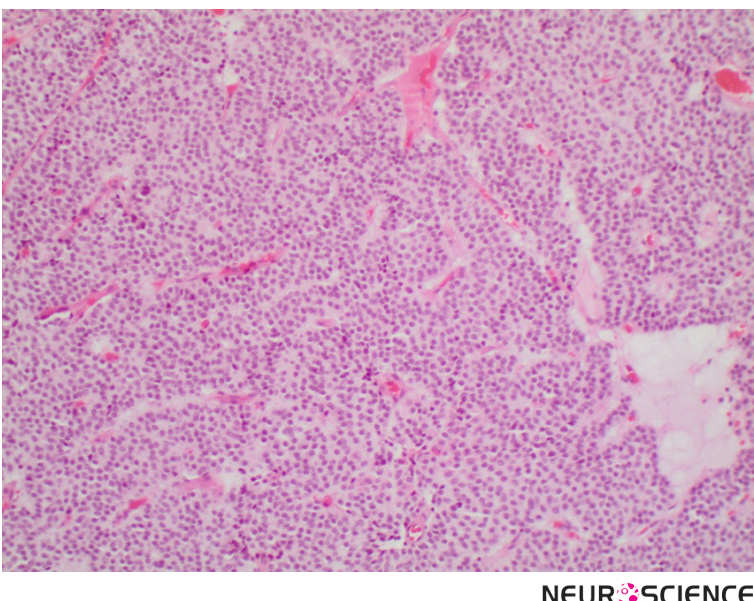

Figure 6. High-power (100x) hematoxylin and eosin (H\&E)staining micrograph showing nests of uniform cells separated by a fine vascular network consistent with pituitary adenoma. The uniform cells contain round nuclei, stippled chromatin and delicately vesicular amphophilic cytoplasm.
An extended endoscopic transsphenoidal approach (EETS) for resection of both pituitary macroadenoma and the suprasellar meningioma was performed uneventfully. The soft, grey-pink pituitary macroadenoma was encountered along with the avascular and firm suprasellar meningioma displacing the optic nerves laterally (Figure 3). Total macroscopic clearance was achieved (Figure 4, 5). Postoperative visual field testing and hormonal evaluation studies were normal.

Based on histopathology report, the pituitary lesion possessed nests of monotonous cells with round nuclei and amphophilic cytoplasm, all of them stained negatively on immunoperoxidase to pituitary hormones $(\mathrm{LH}$, FSH, GH, TSH, PRL, ACTH) confirming the diagnosis of non-functioning pituitary adenoma (NFPA) (Figure 6). The second suprasellar tumour was composed of spindle cells with elongated oval nuclei arranged irregularly and in whorls, consistent with WHO grade 1 meningioma (Figure 7).

\section{Discussion}

Although the association of meningioma and pituitary adenoma in patients without previous irradiation has been reported, it is extremely rare (Abs et al., 1993; Mahvash, Igressa, Pechlivanis, Weber, \& Charalampaki, 2014; Maiuri, Cappabianca, Iaconetta, Esposito, \& Messina, 2005; Prevedello et al., 2007). Most of the cases include growth-hormone-producing adenoma associated with a single meningioma (Abs et al., 1993; Maiuri et al., 2005). This association has been theorised to be due to persistently elevated growth-hormone inducing and

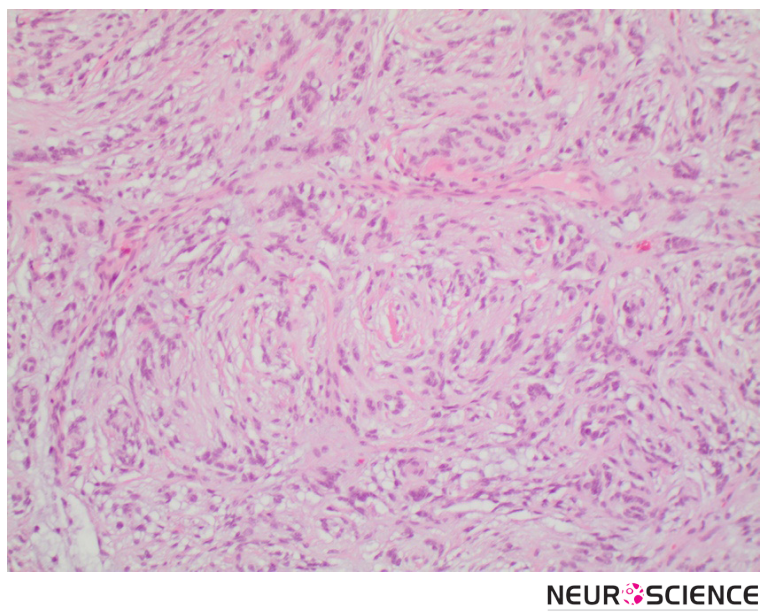

Figure 7. High-power (100x) hematoxylin and eosin (H\&E)stained micrograph demonstrating a section with spindle cells containing elongated, oval nuclei, some of which contain nuclear pseudoinclusions and finely vesicular amphophilic cytoplasm, arranged in an irregular whorl-like pattern, consistent with benign meningioma. 
stimulating growth of arachnoid cap cells into meningioma (Maiuri et al., 2005).

Here, we present a case of NFPA with concurrent suprasellar and olfactory meningiomas in a radiation-naïve patient. To our knowledge, this is the first such reported case. Abs et al. (1993) observed a NFPA with concurrent meningiomas in sphenoid ridge and parasellar region in an elderly lady. However, the meningiomas were not resected and it is unclear if the patient has previous cranial irradiation.

Fifty percent of NFPA cases display growth with long term follow-up (Dekkers et al., 2007). On the other hand, meningiomas can have variable growth rate: some plateau in size or grow very slowly (Sughrue et al., 2010). Being mostly benign, NFPAs or meningiomas can be managed conservatively with serial imaging or surgical resection.

The presence of multiple meningiomas concurrent with a pituitary macroadenoma in our case presented a challenge in management strategies. EETS often requires the collaboration between ENT and neurosurgeons. It is commonly utilised to approach pituitary region tumours for its excellent visualisation and access to tumours whilst avoiding the need for craniotomy and lowering perioperative complication rates (Oostra, van Furth, \& Georgalas, 2012; Koutourousiou et al., 2014a). This is further supported by reports of EETS for resection of synchronous suprasellar meningioma and pituitary adenoma in a single approach with success, when traditionally 2 separate operations would have been required for dual tumours in the parasellar region (Prevedello et al., 2007; Mahvash et al., 2014).

Although EETS is increasingly accepted for resection of anterior skull base meningiomas with gross total rate of resection at $63 \%-67 \%$, its use in resecting a concurrent OGM together with the pituitary region tumours has not been reported (Komotar, Starke, Raper, Anand, \& Schwartz, 2012; Koutourousiou, Fernandez-Miranda, Wang, Snyderman, \& Gardner, 2014b). We believe that such procedure in our patient would have necessitated a much more extensive approach with higher surgical complication risk, including cerebrospinal fluid leaks and inevitable anosmia (Komotar et al., 2012). Our decision to manage the OGM conservatively was supported by a review by Sughrue et al. (2010) concluding the size of meningioma at diagnosis being a predictor for its growth pattern, with only $2 \%$ of untreated meningiomas smaller than $20 \mathrm{~mm}$ in size going on to develop new symptoms in 5 -year-period compared to $42 \%$ in larger meningiomas.
In conclusion, this is the first reported case, to our knowledge, of pituitary adenoma with concurrent olfactory groove and tuberculum sella meningiomas.

\section{Acknowledgments}

The current research hasn't received any financial support.

\section{Conflict of Interest}

All authors declared no conflict of interest.

\section{References}

Abs, R., Parizel, P. M., Willems, P. J., Van de Kelft, E., Verlooy, J., Mahler, C., et al. (1993). The association of meningioma and pituitary adenoma: report of seven cases and review of the literature. European Neurology, 33(6), 416-22.

Dekkers, O. M., Hammer, S., de Keizer, R. J. W., Roelfsema, F., Schutte, P. J., Smit, J. W. A., et al. (2007). The natural course of non-functioning pituitary macroadenomas. European Journal of Endocrinology, 156(2), 217-24. doi: 10.1530/eje.1.02334

Komotar, R. J., Starke, R. M., Raper, D. M. S., Anand, V. K., \& Schwartz, T. H. (2012). Endoscopic skull base surgery: a comprehensive comparison with open transcranial approaches. British Journal of Neurosurgery, 26(5), 637-48. doi: 10.3109/02688697.2012.654837

Koutourousiou, M., Fernandez-Miranda, J. C., Stefko, S. T., Wang, E. W., Snyderman, C. H., \& Gardner, P. A. (2014a) Endoscopic endonasal surgery for suprasellar meningiomas: experience with 75 patients. Journal of Neurosurgery, 120(6), 1326-339. doi: 10.3171/2014.2.JNS13767

Koutourousiou, M., Fernandez-Miranda, J. C., Wang, E. W., Snyderman, C. H., \& Gardner, P. A. (2014b). Endoscopic endonasal surgery for olfactory groove meningiomas: outcomes and limitations in 50 patients. Neurosurgical Focus, 37(4), 8. doi: $10.1055 / \mathrm{s}-0035-1546518$

Mahvash, M., Igressa, A., Pechlivanis, I., Weber, F., \& Charalampaki, P. (2014). Endoscopic endonasal transsphenoidal approach for resection of a coexistent pituitary macroadenoma and a tuberculum sellae meningioma. Asian Journal of Neurosurgery, 9(4), 236. doi: 10.4103/1793-5482.146629

Maiuri, F., Cappabianca, P., Iaconetta, G., Esposito, F., \& Messina, A. (2005). Simultaneous presentation of meningiomas with other intracranial tumours. British Journal of Neurosurgery, 19(4), 368-75. doi: 10.1080/02688690500305548

Oostra, A., van Furth, W., \& Georgalas, C. (2012). Extended endoscopic endonasal skull base surgery: from the sella to the anterior and posterior cranial fossa. ANZ Journal of Surgery, 82(3), 122-30. doi: 10.1111/j.1445-2197.2011.05971.x

Prevedello, D. M., Thomas, A., Gardner, P., Snyderman, C. H., Carrau, R. L., \& Kassam, A. B. (2007). Endoscopic endonasal resection of a synchronous pituitary adenoma and a tuberculum sellae meningioma: technical case report. Neurosurgery, 60(4), 401. doi: 10.1227/01.NEU.0000255359.94571.91 
Sughrue, M. E., Rutkowski, M. J., Aranda, D., Barani, I. J., McDermott, M. W., \& Parsa, A. T. (2010). Treatment decision making based on the published natural history and growth rate of small meningiomas. Journal of Neurosurgery, 113(5), 1036-042. doi: 10.3171/2010.3.JNS091966 